\title{
ORGANIZAÇÃO DO TRABALHO EM UMA COOPERATIVA DE RECICLAGEM: IMPLICAÇÕES PARA A SAÚDE DE CATADORAS*
}

\author{
Alexa Pupiara Flores Coelho ${ }^{1}$, Carmem Lúcia Colomé Beck², Marcelo Nunes da Silva Fernandes ${ }^{3}$, Rosângela \\ Marion da Silva ${ }^{2}$, Daiane Aparecida Martins do Reis ${ }^{4}$
}

\begin{abstract}
RESUMO: Objetivou-se analisar a organização do trabalho de mulheres catadoras de materiais recicláveis de uma cooperativa da região central do Rio Grande do Sul, Brasil. Trata-se de um estudo qualitativo, exploratóriodescritivo realizado entre julho e agosto de 2013 e os dados oriundos de observação participante e de sessões de grupo focal. Os dados foram analisados segundo análise temática de conteúdo. Os resultados evidenciaram que, apesar das trabalhadoras possuírem afinidade por determinadas tarefas, as dificuldades determinam a organização das tarefas na cooperativa. A organização do trabalho é influenciada pela divisão do trabalho, carência de recursos humanos (o que implica em sobrecarga) e de equipamentos adequados. Aponta-se para a necessidade de amparo trabalhista e rede de cuidados para a catadora de materiais recicláveis, frente às dificuldades laborais.
\end{abstract}

DESCRITORES: Saúde do trabalhador; Condições de trabalho; Catadores; Enfermagem.

\section{ORGANIZATION OF THE WORK IN A RECYCLING COOPERATIVE: IMPLICATIONS FOR THE HEALTH OF FEMALE WASTE PICKERS}

\begin{abstract}
This study aimed to analyze the organization of the work of female waste pickers in a cooperative in the central region of the state of Rio Grande do Sul, Brazil. It is a qualitative, exploratory-descriptive study undertaken between July - August 2013, with data arising from participant observation and focus group sessions. The data were analyzed using thematic content analysis. The results evidence that, in spite of the workers having affinity for specified tasks, it is the difficulties that determine the organization of tasks in the cooperative. The organization of the work is influenced by the division of the work, and the lack of human resources (entailing overload) and appropriate equipment. The study points to the need for occupational support and a care network for female waste pickers, in the light of the occupational difficulties.
\end{abstract}

DESCRIPTORS: Occupational health; Working conditions; Solid waste segregators; Nursing.

\section{ORGANIZACIÓN DEL TRABAJO EN UNA COOPERATIVA DE RECICLAMIENTO: IMPLICACIONES PARA LA SALUD DE CATADORAS}

RESUMEN: El objetivo del estudio fue analizar la organización del trabajo de mujeres catadoras de materiales reciclables de una cooperativa de la región central de Rio Grande do Sul, Brasil. Es un estudio cualitativo, exploratorio descriptivo realizado entre julio y agosto de 2013. Los datos fueron obtenidos por medio de observación participante y de sesiones de grupo focal y analizados de acuerdo al análisis temático de contenido. Los resultados evidenciaron que, a pesar de la afinidad de las trabajadoras por determinadas tareas, las dificultades determinan la organización de las tareas en la cooperativa. La organización del trabajo es influenciada por la división del trabajo, así como carencia de recursos humanos (lo que trae sobrecarga) y equipos adecuados. Se apunta la necesidad de soporte de trabajo y red de cuidados para la catadora de materiales reciclables delante de las dificultades laborales.

DESCRIPTORES: Salud laboral; Condiciones de trabajo; Segregadores de residuos sólidos; Enfermería.

*Artigo extraído do Trabalho de Conclusão de Curso intitulado: "Adoecimento relacionado ao trabalho em mulheres selecionadoras de materiais recicláveis". Universidade Federal de Santa Maria, 2014.

${ }^{1}$ Enfermeira. Mestranda do Programa de Pós-Graduação em Enfermagem da Universidade Federal de Santa Maria. Santa Maria, RS, Brasil.

${ }^{2}$ Enfermeira. Doutora em Enfermagem. Docente do Departamento de Enfermagem da Universidade Federal de Santa Maria. Santa Maria, RS, Brasil.

${ }^{3}$ Enfermeiro. Mestre em Enfermagem. Enfermeiro da Estratégia de Saúde da Família da Prefeitura Municipal de Santa Maria. Santa Maria, RS, Brasil.

${ }^{4}$ Discente de Enfermagem da Universidade Federal de Santa Maria. Santa Maria, RS, Brasil. 


\section{- INTRODUÇÃO}

A Saúde do Trabalhador compreende um campo que contempla estudos e intervenções direcionados à articulação entre trabalho e saúde, primando pela promoção e proteção à qualidade de vida dos trabalhadores ${ }^{(1)}$. Muito além de ações locais e individualizadas, a Saúde do Trabalhador concebe uma prática que contemple o coletivo de trabalho e que considere todos os determinantes físicos, sociais, culturais e psíquicos do trabalho como fundamentais no processo saúde e doença.

Na década de 70, o psicanalista francês Christophe Dejours estudou a mobilização subjetiva provocada pelo labor, criando assim a Psicodinâmica do Trabalho, que se dedica a compreender o equilíbrio entre as vivências de prazer e sofrimento no trabalho, do qual depende a manutenção da saúde psíquica do trabalhador ${ }^{(2)}$. Assim, os estudos em Psicodinâmica do Trabalho contemplam a implicação do trabalho na integridade psíquica dos indivíduos, tendo em vista que a análise psicodinâmica objetiva o estudo dos movimentos psicoafetivos desencadeados pelos movimentos inter e intrassubjetivos envolvidos nas experiências do trabalhar ${ }^{(3)}$.

O elemento central da dinâmica saúde e doença do trabalhador é, segundo a teoria psicodinâmica, a organização do trabalho, que inclui um conjunto amplo de elementos de ordem burocrática, hierárquica e estrutural representados pela divisão das tarefas e pelo modo como os indivíduos se organizam e se relacionam nas atividades laborais ${ }^{(4)}$. A organização do trabalho prescreve ao trabalhador normas e regras, as quais se confrontam com seus desejos e sua singularidade; o grau de autonomia do sujeito que trabalha sobre a organização e sua liberdade em imprimir ao trabalho seu "modo de fazer" determina vivências de prazer ou de sofrimento e influenciam na dinâmica saúde e doença ${ }^{(2)}$.

Frente a esse processo, é necessário direcionar o olhar para o trabalho feminino. Sabe-se que o trabalho feminino está inserido em um contexto no qual a mulher frequentemente está sujeita a condições precárias, devido à falta de amparo e às condições sociais, culturais e legais desfavoráveis. Isso diz respeito ao fato de que à mulher se destinam, muitas vezes, ocupações informais, de extensa jornada de trabalho, de baixo rendimento resultante, pouco flexíveis e de pouco reconhecimento social, como o trabalho doméstico, comércio ambulante, a catação de materiais recicláveis, entre outros $^{(5)}$.

Dentre essas mulheres, vai se abordar neste estudo a catadora de materiais recicláveis, trabalhadora que, muitas vezes, não é beneficiada pelas ações de proteção à saúde do trabalhador previstas na legislação ${ }^{(6)}$. Estes fatores justificam a necessidade de se discutir sua saúde, dada sua exposição às vivências de sofrimento no trabalho, o que constitui um tema fundamental a ser considerado no campo de enfermagem. Considera-se relevante que a enfermagem se aproprie dos estudos e ações no campo da saúde do trabalhador, trabalho feminino e catador de materiais recicláveis, dado o seu papel na promoção de saúde, prevenção de doenças e acidentes e na educação para o trabalho seguro, sobretudo dentre os grupos mais vulneráveis. Portanto, conhecer o modo como estes grupos se relacionam com o trabalho e sua organização representa um ponto de partida para a construção destas ações.

O presente estudo, portanto, teve por objetivo analisar a organização do trabalho de mulheres catadoras de materiais recicláveis de uma cooperativa da região central do Rio Grande do Sul, Brasil.

\section{MÉTODO}

O presente estudo constituiu-se de uma investigação qualitativa, do tipo exploratório-descritivo. O cenário de pesquisa foi uma cooperativa de reciclagem localizada em um município da região central do Rio Grande do Sul, Brasil.

Os participantes foram mulheres catadoras de materiais recicláveis dessa cooperativa, escolhidas mediante os critérios de inclusão: ser mulher trabalhadora em atividades de catação de materiais recicláveis vinculada à cooperativa e atuar há, pelo menos, seis meses na atividade em questão. O critério de exclusão consistiu em: trabalhadoras que estivessem afastadas do trabalho no período da produção de dados por qualquer motivo. 
Ressalta-se que este artigo traz resultados referentes a uma das interfaces do Trabalho de Conclusão de Curso intitulado "Adoecimento relacionado ao trabalho em mulheres selecionadoras de materiais recicláveis"; os resultados são oriundos da articulação de dois instrumentos de produção de dados: a observação participante e a técnica do grupo focal (GF).

A observação participante prevê o convívio, contato, comunicação e troca de experiências entre pesquisador, participantes e o contexto dinâmico das relações constituído entre eles ${ }^{(7)}$. Esta etapa foi realizada no mês de julho de 2013. O cenário de pesquisa foi a cooperativa de reciclagem, sendo que o foco das observações foi a dinâmica de trabalho das mulheres, utilizando-se para isso roteiro de observação e diário de campo.

Já o GF é uma técnica de produção de dados que possibilita inserir os participantes, de maneira coletiva, em um processo de discussão e reflexão, no sentido de repensar atitudes, concepções, práticas e políticas sociais ${ }^{(8)}$. Foram realizadas três sessões, com cinco participantes na primeira, cinco na segunda e seis na terceira. Os encontros foram realizados na cozinha da cooperativa e tiveram a duração de, aproximadamente, uma hora cada. As sessões de GF contaram com a presença de um moderador, responsável pela condução dos debates, e de três assistentes de pesquisa, envolvidos nos registros da linguagem não verbal e elaboração de uma síntese das discussões que, ao final, era lida às participantes. As trabalhadoras foram identificadas, nas transcrições, por nomes fictícios escolhidos por cada uma delas.

Visando facilitar a análise, as sessões de GF foram gravadas mediante o consentimento de todas as participantes, com auxílio de gravadores digitais. Os dados foram submetidos à análise temática de conteúdo, a qual se deu em três etapas: pré-análise; exploração do material; tratamento dos dados e interpretação ${ }^{(9)}$.

O estudo atendeu à Resolução n. 466/12 do Conselho Nacional de Saúde ${ }^{(10)}$, sendo que todas as participantes assinaram o Termo de Consentimento Livre e Esclarecido. A pesquisa foi aprovada pelo Comitê de Ética em Pesquisa da Universidade Federal de Santa Maria (CEP/UFSM) sob número do Certificado de Apresentação para Apreciação Ética (CAAE) 16195113.9.0000.5346.

\section{RESULTADOS}

As participantes encontravam-se na faixa dos 30 aos 53 anos de idade. Dentre as seis participantes, cinco moravam com companheiro e possuíam filhos. O tempo de trabalho na reciclagem variou de 3,5 a 19 anos. Todas eram alfabetizadas, sendo que a trabalhadora com menor escolaridade possuía a quarta série do ensino fundamental completa e a mais escolarizada contava com ensino superior incompleto.

As mulheres catadoras de materiais recicláveis realizavam uma jornada de trabalho de, aproximadamente, 45 horas semanais. Seu horário de trabalho era das oito às dezessete horas e trinta, com uma hora de intervalo para o almoço.

A cooperativa se organiza entre o trabalho do galpão de reciclagem e o trabalho nos caminhões. No galpão, as mulheres separam os materiais recicláveis por tipos na esteira ou mesa para, posteriormente, ser prensados e transformados em fardos. Após, os fardos são empilhados e passam a aguardar a venda ou a destinação a outra cooperativa de menor porte, cadastrada na coleta seletiva municipal. Além disso, existe o tratamento dos papéis chamado "sigilo" (pois os documentos devem ser tratados de maneira que todas as informações neles contidas não possam ser identificadas). Os papéis são separados em dois tipos (brancos e coloridos/escuros), são picados e, por último, prensados e transformados em fardos. Quanto ao trabalho nos caminhões, é realizado por homens, havendo a inclusão das mulheres do galpão quando falta mão-de-obra masculina.

Durante a observação participante, constatou-se que no interior do galpão, as mulheres geralmente realizavam as mesmas tarefas e ocupavam os mesmos postos de trabalho. Percebeu-se que a divisão do trabalho se dava por afinidade, o que foi confirmado durante os GF:

Cada um tem a sua função, as gurias sabem fazer na mesa, eu sei fazer o papel, é a função que sabe. (Patrícia) 
[...] A "Nina" é boa na mesa, não adianta colocar ela a fazer outra coisa porque ela vai render menos [...] Não adianta me colocarem na mesa, porque eu não vou render. Porque o meu foco é a sucata, eu sei fazer sucata. Não precisa elas me dizerem, eu sei que eu não consigo produzir, porque não é o trabalho que eu estou acostumada no dia-a-dia. (Mônica)

No entanto, o trabalho na cooperativa apresentava um conjunto de questões operacionais que interferiam no modo como sua organização era moldada. A alta exigência das tarefas e, principalmente, a falta de pessoal faziam muitas vezes com que as trabalhadoras fossem obrigadas a interromper suas tarefas e abandonar seu posto de trabalho, aquele com o qual se identificavam e tinham afinidade, para ocupar outro posto ou ajudar a colega que estava com dificuldades. Essa situação configurava um "vai-e-vem" das trabalhadoras em diversas tarefas ao longo do dia, na maioria das vezes, para resolver problemas urgentes.

Em relação ao número reduzido de pessoal, as mulheres atribuíam isso a dois fatores: às faltas frequentes de alguns colegas e à alta rotatividade de pessoas, pois afirmavam que muitos procuravam a cooperativa em busca de trabalho, mas o abandonavam em pouco tempo.

[...] O pessoal vem aqui, a gente dá serviço, o pessoal acha que é fácil aqui. Chega na hora de pegar no pesado, de levantar fardo para o terceiro, quarto andar, o pessoal se manda. Para tu veres, as guerreiras que estão aqui somos nós mesmas, as antigas, somos nós que estamos aí, tocando. (Patrícia)

A gente percebe uma dificuldade que os mais antigos dificilmente faltam. Faltam, mas não é tanto como as pessoas que entraram há pouco. E é onde elas "quebram a gente", porque isso aqui é uma engrenagem, se faltar um dente, a engrenagem para de funcionar. (Mônica)

Em decorrência das dificuldades relacionadas à divisão do trabalho, as mulheres se viam obrigadas a dar conta de vários tipos de atividades. Segundo as trabalhadoras, a falta de pessoal para a organização das tarefas acarretava em sobrecarga, conforme ilustram os trechos:

[...] Porque se falta gente, tu tens que trabalhar por ti e pela pessoa que faltou. Aí complica. E ontem faltaram três. [...] Falta gente, daí vai acumulando. Uma, duas não vão dar conta do material que chega; dois, três caminhões por dia. (Patrícia)

Ainda em relação às dificuldades relacionadas à organização do trabalho, as mulheres colocaram a questão da divisão das tarefas entre homens e mulheres na cooperativa. Segundo elas, havia uma dificuldade na prestação de auxílio dos homens para o trabalho no galpão. Enquanto as mulheres se sentiam sobrecarregadas com as atividades no galpão e nos caminhões, os homens se limitavam aos caminhões e, ao final do dia, iam para as suas casas, enquanto que as mulheres permaneciam no galpão após o término do turno de trabalho para dar conta das atividades acumuladas.

[...] Tu podes estar ali "botando os bofes para fora" para levantar um fardo, que eles chegam e dizem "minha parte tá pronta e deu" [...] Antes eles chegavam e iam nos ajudar, recolher o que estava na rua, ajudar a levantar fardo, pesar. A gente começou a fazer algumas coisas antes deles chegarem, daí eles não se sentem tão responsáveis quanto deveriam. É uma dificuldade, tu tens que pedir "por favor". (Mônica)

Eles chegam aqui, pegam as coisinhas deles e vão para casa, e nós temos que levantar fardo, temos que trazer o material lá de fora, nós temos que ir no caminhão quando eles faltam. Eles não vêm, nós temos que ir. E eles não podem fazer nosso serviço. A gente pode fazer o deles. (Patrícia)

Estes elementos referentes à divisão do trabalho tangenciaram também as concepções das mulheres acerca do que elas conceituam como "trabalho típico da mulher e do homem". As trabalhadoras mencionaram incompatibilidade entre o homem e o "trabalho da mulher", motivadas pelas experiências do grupo com homens no galpão:

Eles não catam as miudezas que tu catas, que tu fazes, porque eles não têm paciência [...] Não que eu esteja discriminando os homens, que não é para trabalhar aqui, não é isso! Mas tu vês numa mesa, numa separação, é mulher. (Manuela)

Já em relação aos problemas estruturais que permeavam a organização do trabalho na cooperativa, surgiram questões relacionadas ao ambiente físico como espaço e falta de equipamentos apropriados, conforme exemplificam os relatos: 
O nosso primeiro problema é o espaço. Nós tínhamos que ter um espaço maior para poder ter um carrinho, aquela empilhadeira para poder levantar. É que para nós é no lombo, a gente vai lá em cima, é tudo aqui, no braço. É complicado para nós. (Patrícia)

As questões do ambiente já haviam sido constatadas durante a observação participante. O galpão de reciclagem era um ambiente relativamente amplo, mas o fluxo de entrada dos materiais era demasiado para o número de mulheres responsáveis pela triagem, prensa, pesagem e estocagem dos fardos. Isso resultava em um acúmulo de materiais que, não raro, formavam verdadeiros paredões de papelão e plástico. Isso restringia o espaço para o trânsito do pessoal, o que tornava o ritmo de trabalho mais lento. As trabalhadoras reconheceram a importância de condições favoráveis para trabalhar de maneira saudável e mais confortável:

[...] Quando nós iniciamos aqui, a gente não tinha nada dos equipamentos que a gente tem hoje, então a nossa forma de trabalho era muito precária. E hoje não, a gente viu que a gente não precisa sofrer tanto. Se tu tiveres os maquinários, tu consegues trabalhar de uma forma melhor. [...] Porque se tu tiveres os equipamentos certos, tu não judias tanto da tua parte física. Tu consegues produzir sem ter muito esforço para a produção. (Mônica)

As trabalhadoras, portanto, reconheceram que avançaram consideravelmente em termos de condições de trabalho na cooperativa. Mas admitiram que são necessárias novas mudanças e investimentos, no sentido de que o trabalho do catador de materiais recicláveis seja otimizado e favorecido, tendo em vista a manutenção da sua saúde.

\section{- DISCUSSÃO}

Em relação à dinâmica e organização do trabalho, percebe-se semelhança com outras cooperativas brasileiras descritas na literatura nacional(11-12). Destaca-se a divisão do trabalho pautada na afinidade, aptidão e singularidade de cada trabalhadora e a importância disso para seu bem estar. Segundo a Psicodinâmica do Trabalho ${ }^{(4)}$, para a manutenção de sua saúde psíquica, o trabalhador necessita que a organização lhe permita liberdade suficiente para que ele negocie entre as imposições organizacionais e seus desejos. A flexibilidade da organização do trabalho, portanto, é fundamental para que o trabalhador seja capaz de exercer sua autonomia, sua criatividade e sua subjetividade tornando, portanto, o ato de trabalhar num mediador de prazer.

Porém, a esse modelo de divisão do trabalho, confrontaram-se a realidade do dia-a-dia das catadoras desta pesquisa, as dificuldades em relação aos recursos humanos e à dinâmica laboral, que faziam com que as trabalhadoras fossem desacomodadas de seus postos em função das necessidades do serviço. A isso corresponde o trabalho real, definido pela Psicodinâmica do Trabalho ${ }^{(13)}$ como tudo aquilo que o trabalhador realmente faz no seu cotidiano laboral, resultado da interação entre um conjunto de elementos que inclui, principalmente, as situações não previstas e não esperadas, os incidentes, as dificuldades e interferências, os quais o obrigam a se adaptar para dar conta das exigências. Portanto, o trabalho real, dada a exigência de que o indivíduo dê conta de uma demanda urgente, adicional ao que lhe fora prescrito, pode ocasionar sofrimento e desgaste físico e mental.

Autores $^{(14)}$ em estudo junto a catadores de uma associação de reciclagem inferem que estes experenciam uma margem de autonomia e liberdade sobre seu processo de trabalho, uma vez que, no dia-a-dia, praticamente não há prescrições das tarefas, e sim "modos de fazer" transmitidos através da práxis e permanentemente reconstruídos pelo coletivo. Corrobora-se em parte com os autores, uma vez que, se por um lado o trabalho cooperativado possibilita certo controle sobre a organização, por outro lado esta organização é influenciada por fatores como a falta de mão-de-obra e más condições laborais, o que determina, muitas vezes, o confronto do trabalhador com a realidade do trabalho.

O conflito entre a organização real do trabalho e as características psíquicas do trabalhador pode ocasionar adoecimento ${ }^{(13)}$. Se as mulheres catadoras de materiais recicláveis encontram-se envolvidas em uma dinâmica laboral que impede a negociação com a realidade e que oprime sua subjetividade e liberdade de trabalhar da maneira que apreciam e desejam, o sofrimento psíquico advindo dessa realidade pode transformar-se em adoecimento ${ }^{(12)}$. 
Considera-se que o bem estar e o prazer estão refletidos na liberdade de cada indivíduo em relação à organização da própria vida, e, por conseguinte, do próprio labor. Esta necessidade de liberdade se estende ao conteúdo do trabalho, à divisão das tarefas e à relação existente entre si e com os outros ${ }^{(15)}$. Portanto, fica evidente a interlocução entre a satisfação do trabalhador com a organização de sua atividade laboral e seu bem estar, suas vivências de prazer no trabalho e, consequentemente, sua saúde.

Em relação à escassez de recursos humanos que ocasionava a sobrecarga para as trabalhadoras, observa-se que as mesmas encontravam obstáculos para recrutar pessoal que se adaptasse ao trabalho, o que pode ser resultado das dificuldades relacionadas ao contato com materiais recicláveis. Sobre isso, supõe-se que nem todas as pessoas conseguem se enquadrar e se identificar com o ritmo e as exigências do dia-a-dia na cooperativa, o que resulta em evasão da mão-de-obra iniciante.

Acerca disto, pesquisa ${ }^{(16)}$ sobre as representações sociais de catadores no que tange ao seu trabalho mostrou que os mesmos sentem-se marcados pela imagem do trabalhador sujo, com mau odor, miscigenado ao lixo onde trabalhada, imagem esta que culmina em sentimentos de exclusão e repulsa social. Esse fator, associado à alta exigência física das tarefas, pode estar envolvido na dificuldade encontrada para engajar trabalhadores que se identifiquem com as atividades de reciclagem.

Outro elemento presente nos depoimentos é a divisão sexual do trabalho, a qual diz respeito à delimitação de tarefas entre os trabalhadores a partir do critério de gênero. Pesquisa etnográfica ${ }^{(12)}$ realizada em um galpão de reciclagem evidenciou profundas marcas do gênero na divisão das tarefas entre os homens e as mulheres. Segundo o estudo, à mulher é destinado o trabalho que se considera de maior "minúcia, cuidado e sensibilidade", o que remete à concepção pré-estabelecida da natureza doméstica da mulher. Já ao homem é destinado o trabalho que se considera exigir maior força, raciocínio e inteligência.

Essa afirmação corrobora as concepções que as mulheres apresentaram ao longo da pesquisa em relação ao trabalho desempenhado por elas e pelos homens. A divisão sexual do trabalho e as desvantagens sofridas pela mulher acarretam graves implicações à vida e à saúde das trabalhadoras ${ }^{(17)}$. Considera-se que a construção do masculino e do feminino resulta de relações socialmente estabelecidas, as quais implicam em inferioridade e desigualdades ${ }^{(18)}$. Portanto, a permanência da divisão sexual das tarefas colabora para a restrição do seu espaço no mundo laboral e para a precarização do seu trabalho, o que pode ter implicações no sofrimento e adoecimento psíquico.

A Psicodinâmica do Trabalho destaca que as relações humanas nos ambientes laborais sofrem influências das diferentes formas de organização do trabalho. Isso aponta para o fato de que existe uma estreita articulação entre os modelos organizacionais e a subjetividade dos trabalhadores ${ }^{(15)}$. Portanto, pode-se compreender que o modo como o trabalho dos catadores está configurado é resultado, em parte, dos conflitos pessoais, da dinâmica do coletivo de trabalho, dos movimentos de união e desunião, dos valores concebidos por cada indivíduo e pelo grupo.

Por fim, no que diz respeito aos problemas estruturais e de maquinário presentes na cooperativa, aponta-se para sua potencial implicação na saúde laboral das trabalhadoras. Pesquisa ${ }^{(19)}$ evidenciou que o catador cooperativado encontra-se em um processo cíclico de manutenção de uma situação de exclusão e precarização, influenciado por elementos como as fragilidades de organização do trabalho, barreiras na comercialização, pagamento irrisório pelo material separado e, consequentemente, impossibilidade de investimentos em infraestrutura. Esse processo, segundo os autores, tem reflexos na saúde dos catadores, sobretudo, em sua integridade psíquica.

Concorda-se com autores ${ }^{(20)}$ quando afirmam que, embora os catadores de materiais recicláveis sejam trabalhadores fundamentais para a construção de uma cadeia de reciclagem efetiva, eles sofrem com a falta de bens materiais, amparo social, financeiro e psicológico, além do real reconhecimento de suas necessidades e importância. O reconhecimento desse trabalhador e a construção de redes de cuidado podem ser importantes para a promoção de melhorias em seus ambientes e, consequentemente, na organização do seu trabalho.

O catador de materiais recicláveis, dada sua exposição, necessita de atenção especial, especialmente por parte dos profissionais de saúde ${ }^{(21)}$. O enfermeiro possui papel fundamental nesse processo, dada 
sua posição como educador, gerente dos serviços de saúde e ator nos diferentes níveis de assistência. O exercício profissional da enfermagem se estende a ações de promoção de saúde e segurança no trabalho, bem como educação para a redução dos riscos físicos e psíquicos oriundos das atividades laborais. Portanto, conhecer a organização do trabalho pela voz dos próprios trabalhadores representa um caminho para compreender seus sentimentos e necessidades.

Destaca-se o trabalho, na perspectiva psicodinâmica, como elemento fundamental na construção do ser humano, atuando como mediador entre o inconsciente e o campo social, o singular e o coletivo. Isso permite pensar que o trabalho em si não representa agente permanente de sofrimento e desgaste, mas a maneira como ele é organizado pelos indivíduos ${ }^{(15)}$. Portanto, novas concepções de organização devem ser buscadas, no sentido de resgatar-se o prazer, a saúde e o próprio trabalhador dentro do exercício da sua autonomia e liberdade.

\section{CONSIDERAÇÕES FINAIS}

Este estudo mostrou que a organização do trabalho na cooperativa de reciclagem é influenciada pela escassez de recursos humanos que ocasiona sobrecarga e desgaste para as trabalhadoras; insatisfação na divisão do trabalho; problemas estruturais na área física e de equipamentos. Esses fatores podem tornar o desempenho das tarefas mais difícil e por em risco a saúde e o bem estar das catadoras.

Considera-se que este estudo contribui no sentido de tornar visível à sociedade e à pesquisa em enfermagem uma interface referente à vulnerabilidade vivenciada pela mulher catadora de materiais recicláveis. É fundamental que esta receba amparo, cuidados e maior atenção por parte do campo da saúde, sendo primordial a articulação de uma rede de cuidados convergente com suas necessidades.

A enfermagem se encontra diante do desafio de desenvolver estudos e ações de intervenção que contribuam para o acesso dos mais diferentes grupos de indivíduos à prevenção de acidentes e agravos à saúde. No que tange aos catadores de materiais recicláveis, este desafio exige a compreensão da organização do seu trabalho e dos demais elementos que estão relacionados às vivências de prazer e sofrimento, saúde e doença. Portanto, compreender a dinâmica existente entre saúde e trabalho é fundamental para que o enfermeiro seja capaz de promover melhorias e construir planos de cuidados aos trabalhadores vulneráveis.

Como limitação do estudo, menciona-se o fato de que muitas catadoras se sentiram pouco à vontade para a fala coletiva. Além disso, aponta-se a impossibilidade de generalizações dos resultados, por se tratar de uma realidade específica, ou seja, uma cooperativa de reciclagem de um município da região central do Rio Grande do Sul, Brasil. No entanto, considera-se que os resultados encontrados proporcionam visibilidade a uma temática ainda pouco explorada e pode balizar a realização de estudos interventivos que lancem mão das informações desveladas para a construção de planos de cuidado e ação que convirjam para a saúde dos catadores.

\section{- REFERÊNCIAS}

1. Forte ECN, Trombetta AP, Pires DEP, Gelbcke FL, Lino MM. Theoretical approaches in occupational health of nursing workers: an integrative review. Cogitare enferm. [Internet] 2014; 19(3) [acesso em 21 jul 2015]. Disponível: http://dx.doi.org/10.5380/ce.v19i3.35379.

2. Dejours C. Addendum: da psicopatologia à psicodinâmica do trabalho. In: Lancman S, Sznelwar LI, Idal L, organizadores. Christophe Dejours: da psicopatologia à psicodinâmica do trabalho. Rio de Janeiro (RJ): Fiocruz; 2008. p. 49-106.

3. Augusto MM, Freitas LG, Mendes AM. Vivências de prazer e sofrimento no trabalho de profissionais de uma fundação pública de pesquisa. Psicol. rev. [Internet] 2014; 20(1) [acesso em 21 jul 2015]. Disponível: http:// periodicos.pucminas.br/index.php/psicologiaemrevista/article/view/P.1678-9523.2014v20n1p34/7145.

4. Dejours C. A loucura do trabalho: estudo de psicopatologia do trabalho. $5^{a}$ ed. ampliada. São Paulo: Cortez Oboré; 1992. 
5. Garcia MRV, Segre A, Baccaro AF, Silva LM, Costa L, Cândido MS. "Mulheres guerreiras": identidade feminina e profissional entre vendedoras ambulantes da cidade de São Paulo. Cad. Psicol. Soc. Trab. [Internet] 2010; 13(1) [acesso em 04 jan 2015]. Disponível: http://dx.doi.org/10.11606/issn.1981-0490.v13i1p27-42.

6. Rozman MA, Azevedo CH, Jesus RRC, Filho RM, Junior VP. Anemia in recyclable waste pickers using human driven pushcarts in the city of Santos, southeastern Brazil. Rev. bras. epidemiol. [Internet] 2010; 13(2) [acesso em 18 jul 2015]. Disponível: http://dx.doi.org/10.1590/S1415-790X2010000200014.

7. Spradley JP. Participant observation. New York: Holt, Rinehart and Winston Ed; 1980.

8. Backes DS, Colomé JS, Erdmann RH, Lunardi VL. Grupo focal como técnica de coleta e análise dos dados em pesquisas qualitativas. O Mundo da saúde. [Internet] 2011; 35(4) [acesso em 18 jul 2015]. Disponível: http://bvsms. saude.gov.br/bvs/artigos/grupo_focal_como_tecnica_coleta_analise_dados_pesquisa_qualitativa.pdf.

9. Bardin L. Análise de Conteúdo. $7^{\mathrm{a}}$ ed. Portugal: Geográfica Editora; 2011.

10. Ministério da Saúde (BR). Conselho Nacional de Saúde. Diretrizes e normas regulamentadoras de pesquisa envolvendo seres humanos Resolução n. 466, de 12 de dezembro de 2012. Brasília; 2012.

11. Ribeiro IM, Nardi HC, Machado PS. Catadoras(es) de materiais recicláveis e as possíveis articulações entre trabalho precário e relações de gênero. Cad. Psicol. Soc. Trab. [Internet] 2012; 15(2) [acesso em 18 jul 2015$].$ Disponível: http://dx.doi.org/10.11606/issn.1981-0490.v15i2p243-254.

12. Gutierrez RF, Zanin M. A relação entre tecnologias sociais e economia solidária: um estudo de caso em uma cooperativa de catadores de resíduos. RBDR. [Internet] 2013; 1(1) [acesso em 18 jul 2015]. Disponível: http:// dx.doi.org/10.7867/2317-5443.2013v1n1p129-148.

13. Dejours C. Subjetividade, trabalho e ação. Prod. [Internet] 2004; 14(3) [acesso em 18 jul 2015]. Disponível: http://dx.doi.org/10.1590/S0103-65132004000300004.

14. Sícoli JL. Resíduos de decisão e suas repercussões à saúde dos trabalhadores em uma cooperativa de reciclagem. Cad. Psicol. Soc. Trab. [Internet] 2014;17(1) [acesso em 18 jul 2015]. Disponível: http://pepsic.bvsalud. org/pdf/cpst/v17n1/a02v17n1.pdf.

15. Martins JT, Robazzi MLCC, Bobroff MCC. Pleasure and suffering in the nursing group: reflection to the light of Dejour psychodynamics. Rev. esc. enferm. USP [Internet] 2010; 44(4) [acesso em 25 nov 2015]. Disponível: http://dx.doi.org/10.1590/S0080-62342010000400036.

16. Pereira ER, Silva RMCRA, Mello FP, Oliveira DC, Silva MA. Representações sociais dos catadores de um aterro sanitário: o convívio com o lixo. Psicologia: teoria e prática. [Internet] 2012; 14(3) [acesso em 18 jul 2015$].$ Disponível: http://pepsic.bvsalud.org/pdf/ptp/v14n3/v14n3a03.pdf.

17. Prazeres TJ, Navarro VL. Na costura do sapato, o desmanche das operárias: estudo das condições de trabalho e saúde das pespontadeiras na indústria de calçados de Franca, São Paulo, Brasil. Cad. Saúde Pública. [Internet] 2011; 27(10) [acesso em 18 jul 2015]. Disponível: http://dx.doi.org/10.1590/S0102-311X2011001000006.

18. Cortes LF, Vieira LB, Landerdahl MC, Padoin SMM. Construção do feminino e do masculino: compreensão de uma equipe de enfermagem. Cogitare enferm. [Internet] 2011; 16(2) [acesso em 18 jul 2015]. Disponível: http:// dx.doi.org/10.5380/ce.v16i2.20702.

19. Arantes BO, Borges LO. Catadores de materiais recicláveis: cadeia produtiva e precariedade. Arq. bras. psicol. [Internet] 2013; 65(3) [acesso em 18 jul 2015]. Disponível: http://pepsic.bvsalud.org/pdf/arbp/v65n3/02.pdf.

20. Castilhos Junior AB, Ramos NF, Alves CM, Forcellini FA, Graciolli OD. Catadores de materiais recicláveis: análise das condições de trabalho e infraestrutura operacional no Sul, Sudeste e Nordeste do Brasil. Ciênc. saúde coletiva. [Internet] 2013; 18(11) [acesso em 18 jul 2015]. Disponível: http://dx.doi.org/10.1590/S141381232013001100002.

21. Jesus MCP, Santos SMR, Abdalla JGF, Jesus PBR, Alves MJM, Teixeira N, et al. Avaliação de qualidade de vida de catadores de materiais recicláveis. Rev. eletr. Enf. [Internet] 2012; 14(2) [acesso em 18 jul 2015]. Disponível: http://dx.doi.org/10.5216/ree.v14i2.15259. 